\title{
Essential Role of Crop Landraces for World Food Security
}

\author{
S Alan Walters* \\ Department Plant, Soil, and Agricultural Systems, Southern Illinois University, USA \\ *Corresponding author: S Alan Walters, Department Plant, Soil, and Agricultural Systems, Southern Illinois University, Carbondale, Illinois, USA
}

Submission: 眥January 01, 2018; Published: 㭗April 09, 2018

\begin{abstract}
Cereal grain crops provide most of the energy calories for humans worldwide, and landraces of these crops remain deeply intertwined into the traditions and cultures of many of the world's rural communities. However, due to recent new variety development activities resulting from the "Green Revolution", landraces are in serious jeopardy of being totally lost within the next 50 years. The reduced use of landraces can be traced back to the beginnings of the "Green Revolution", when there was a substantial worldwide increase in the use of new modern cereal crop varieties that provided increased productivity compared to the varieties that were currently in use that had limited genetic improvements.

This movement directly contributed to the depletion of genetic diversity in all crops, although landraces are still used in certain areas for some crops including the major cereal staple food crops. The five most important cereal staple foods in the world (in descending order) are maize (Zea mays), rice (Oryza sativa), wheat (Triticum aestivum), barley (Hordeum vulgare) and sorghum (Sorghum bicolor). A brief overview is presented regarding the problems and issues related to the loss of landraces for these staple food crops.
\end{abstract}

Keywords: Cereals; Crop genetic diversity; Crop population; Staple food crop; Traditional variety

\section{Introduction}

Crop landraces (or local crop varieties) are highly heterogeneous mixtures with slightly differing genotypes that generally produce plant phenotypes having small but often important differences under field conditions. They generally have high amounts of genetic diversity [1,2], but many tend to have lower quality and yields with inconsistent phenotypes compared to newer hybrids and/or even older pure-line inbred varieties [3]. Locally adapted landraces generally produce lower yields during years with optimal environmental conditions than improved varieties, but the relative stability of their yields over years provides food security to subsistence farmers in developing countries [4]. The genetic diversity of landraces is an important part of global crop biodiversity and is considered of paramount importance for future world production [5]. The use of crop landraces continues to be deeply intertwined into the traditions and cultures of many of the world's rural communities. These landraces are dynamic populations of genetically diverse, locally adapted cultivated plant species that have historical origin, distinct identity, no formal crop improvement, and are oftentimes associated with traditional sustainable farming systems [6].
Crop landraces throughout the world are rapidly being lost, due to increasingly more limited use by growers in many areas of the world $[2,7]$. Moreover, lower amounts of field cultivation, multiplication and conservation by growers directly relates to the loss of this valuable genetic resource over time. By saving and planting seeds from crop plants with desirable characteristics, humans over millennia have inadvertently influenced crop evolution, which has allowed the development of landraces adapted to specific different environmental conditions, such as saline soils, temperature extremes, altitude, disease resistances, and drought conditions. The loss of landrace populations is devastating to all crop species gene pools, as genes that have evolved over millennia are being lost from numerous crop plant genomes forever.

The reduced use of landraces can be traced back to the beginnings of the "Green Revolution". During the second half of the 20th century there was a spectacular increase in the production of high yield-cereal crops worldwide, especially corn, rice, and wheat, due to the development of new modern varieties of these crops having greatly increased productivity [8]. Over the years since its beginnings in the late 1960s and early 1970s, the "Green Revolution" has achieved broader and deeper impacts in most 
cropping systems even in remote areas of the world. Since the release of the first modern hybrid varieties in the 1960's, the area planted to these has continued to expand even into remote areas in developing countries [7]. This movement has also contributed to the depletion of genetic diversity in crops.

During the Green Revolution's push towards increased world food production and security, results have largely been successful in satisfying caloric intake requirements with high-starch foods, although this has led to the rapid development of numerous nutritional disorders regarding human health [3]. Landraces are still widely utilized for the major cereal staple food crops in certain areas of the world. Although they have been in a state of decline for years, landraces still play important roles for maintaining food security in developing countries. In contrast, only high yielding modern varieties are used to produce these crops in developed countries.

\section{Staple Food Crop Landrace Overview}

Cereal grains are grown in greater quantities and provide more food energy worldwide than any other type of crop. Crop landraces of all major staple cereal crops are still widely used in certain areas of the world to produce food to prevent mass starvation. The five most important staple food crops in the world, that provide most of the caloric intake to sustain human populations, will briefly be outlined regarding their overall importance, production areas and landrace utilization.

Maize is the most grown cereal in the world based on its total grain production [9]. This crop has varied uses, and although maize provides less than $10 \%$ of the total caloric intake in the world, this grain is the primary source of food energy in some areas of the world. This crop is responsible for providing a high amount of the daily caloric intake in Latin America, Mexico, and northern parts of both Central and South America. Maize plays significant roles in the culture and traditions of indigenous populations in these areas of the Americas. Selection for better taste and texture, ease of preparation, specific kernel colors/shapes/sizes, and ceremonial uses all played a role in the evolution of different maize landraces. Moreover, maize is a significant source of food in many Sub-Saharan African countries, where it is known to provide about half of the total ingested calories.

Maize landraces are still widely used in Mexico, Central and South America, and Africa. Besides being a direct source of food, it is oftentimes used as the primary grain to feed livestock. The genetic diversity of maize must be protected in order to ensure the survival of this important crop species, as well as to maintain the genetic variation for breeding better varieties, especially with the rapidly changing climates across the world.

Rice is the staple food for over half of the human populace and is the second largest cereal based on production [9]. This crop is the most important source of food for most areas in Asia, and to a lesser extent in Central and South America. Although rice is widely consumed as the staple crop in most parts of South Asia and the Far
East, it is also a staple food in most areas of Brazil and many other Latin American countries.

Rice landraces are still widely utilized in many areas of China and India where rice is produced as the most important food source. However, traditional landraces are now progressively being abandoned in China and South East Asia, with replacement by modern highly productive varieties that are provided by governmental assistance programs [10]. This situation will have probable undesirable influences on future rice production in these areas of Asia due to the loss of locally adapted genetic resources.

Wheat is the primary cereal grain produced in temperate regions of the world and ranks as the third most important cereal on a worldwide basis [11]. This crop is widely grown around the world and has been the staple food of the major civilizations in Europe, Asia and North Africa for millennia. Although wheat is consumed worldwide, it is considered a staple food of many developed countries in North America and Europe, as well as in Australia and New Zealand. Wheat is also considered a staple food for most of southern South America and countries in the greater Middle East. Wheat landraces still play an important role in the production of this crop in many of countries in the greater Middle East, such as Turkey and Morocco, where significant amounts of landraces are still grown $[12,13]$. Despite the large number of improved varieties available, the area planted to modern varieties in this region is still insignificant for several reasons, including most importantly, the lack of communication to resource poor, small landholder farmers regarding new technologies.

The presumed center of wheat origin and diversity is situated in the Fertile Crescent [14], which includes portion of this greater Middle East region. Thus, the diversity of wheat and its wild relatives in this region has a global role in providing important genetic resources for wheat improve ment. Moreover, there is significant unexploited variation among wheat landraces and modern wheat cultivars to improve the stress adaptation of cultivated wheat [15].

Barley ranks fourth in world cereal production and is primary known as a source of animal feed or as the primary grain used for malting and brewing [11]. It is an important crop in areas where the climate is cool and dry, such as western North America, northern Europe, Middle East, North Africa, and the Andean region of South America. This crop is often grown on land too poor or in climates that are too cold for wheat to be grown effectively. In the Middle East and North Africa, where drought, heat and salinity high stress environments are common, landraces and/or selections from landraces are considered to be the most dependable genetic materials for farmers to sustainability produce this crop [16]. Barley landraces are of particular importance in the Fertile Crescent region of the Middle East where barley was first domesticated. With the genetic diversity of barley decreasing in areas of its origin and diversification, the risk of severe yield reductions in a single year is increased by calamities such as fungal pathogens, insect pests or unfavorable environmental conditions [17]. 
Sorghum is the fifth most important cereal grown in the world, and an important staple food in semi-arid regions of Asia and Africa [18]. This crop is also widely used worldwide as livestock feed. Sorghum landraces are especially important in West and Central Africa where the grain is a major caloric component of the daily diet for millions of people.

Sorghum originated in Africa, with the Indian Subcontinent being the secondary center of origin. Although the largest diversity of cultivated sorghum is found in Africa, improved varieties are rapidly replacing the lower yielding traditional landraces in some areas. The genetic diversity within African sorghum landraces is especially important for those that depend on this crop as their primary food source to remain food secure for the near-and longterm.

\section{Significant Loss of Staple Crop Genetic Conservation}

The loss of landraces in world production schemes has had a tremendous influence on hindering the amount of on-farm genetic perpetuation and conservation of this diverse and valuable genetic material. Landraces tend to contain high amounts of genetic diversity and are rapidly disappearing at an alarming rate due to limited use by growers in many areas of the world, although their use and perpetuation is really most critical near primary or secondary centers of crop diversity due to alleles present that have evolved over millennia at these locales [19]. As outlined previously, there is definitely a narrowing of the genetic base occurring for all staple food crops, which will have a probable devastating influence on future generations and food production.

\section{Summary}

Staple food crop production is essential to maintain both food security and political stability in world. Although landraces are quickly disappearing for all major staple food crops, they still play important roles that contribute to food security in many developing countries near primary or secondary centers of origin. Traditional agro ecological farming systems tend to rely on methods that reduce input costs, and saving seed to use for the next crop production cycle is one practice used to achieve this goal. However, new variety development and utilization, due to the "Green Revolution's" push to place high yielding, genetically uniform varieties with improved disease and other quality characteristics into many of the world's production schemes, has resulted in the reduced use of landraces. Many of the world's staple crop species still harbor great genetic diversity, having been dispersed to diverse environments and adapted to local conditions under human and natural selection. The resulting diversity of crop landraces remains crucial to global food security, particularly for small land-holder, subsistence agriculture in Africa and Asia, where increasing temperature and erratic precipitation are major threats due to climate change [20].

Landraces provide diverse and dynamic gene pools that evolve over time under both farmer and natural selection pressures. The resulting high amount of genetic diversity allows landraces to adapt to drought, heat, saline soil, or other extreme environmental conditions, which is essential to maintaining long-term productivity especially during periods of erratic climates. Crop landraces originating from stressful environments are a major source of adaptive traits that allow subsistence, small land-holder farmers to cope with growing these staple crops in a changing climate. Without maintaining some level of in situ genetic diversity for these staple food crops, our agricultural future is definitely in jeopardy [3], since these food crops feed the world, provide food security, stabilize economies, and prevent mass starvation.

\section{References}

1. Mazzucato A, Papa R, Bitocchi E, Mosconi P, Nanni L, et al. (2008) Genetic diversity, structure and marker-trait associations in a collection of Italian tomato (Solanum lycopersicum L.) landraces. Theor Appl Genet 116(5): 657-669.

2. Terzopoulos PJ, Walters SA, Bebeli PJ (2009) Evaluations of Greek tomato landrace populations for heterogeneity of horticultural traits. Europ J Hort Sci 74(1): 24-29.

3. Walters SA (2016) Vegetable seed availability and implications for developing countries: A perspective from Morocco. Outlook on Agriculture 45(1): 18-24.

4. Barnaud A, Deu M, Garine E, McKey D, Joly HI (2007) Local genetic diversity of sorghum in a village in northern Cameroon: structure and dynamics of landraces. Theor Appl Genet 114(2): 237-248.

5. Wood D, Lenné JM (1997) The conservation of agro biodiversity on-farm questioning the emerging paradigm. Biodiversity and Conservation 6(1): 109-129.

6. Camancho Villa TC, Maxted ZN, Scholten MA, Ford Lloyd BV (2005) Defining and identifying crop landraces. Plant Genetic Resources 3(3): 373-384.

7. Morris ML, Bellon MR (2004) Participatory plant breeding research: opportunities and challenges for the international crop improvement system. Euphytica 136(1): 21-35.

8. Evenson RE, Gollin D (2003) Assessing the impact of the Green Revolution, 1960 to 2000. Science 300(5620): 758-762.

9. FAOSTAT (2009) Food and Agriculture Organization of the United Nations. Rome, Italy.

10. Ishikawa R, Yamanaka S, Fukuta Y, Chitrakon S, Bounphanousay C, et al. (2006) Genetic erosion from modern varieties into traditional upland rice cultivars (Oryza sativa L.) in northern Thailand. Genet Resour Crop Evol 53(2): 245-252.

11. FAOSTAT (2007) Food and Agriculture Organization of the United Nations. Rome, Italy.

12. Morgounov A, Keser M, Kan M, Küçükçongar M, Özdemir F, et al. (2016) Wheat landraces currently grown in Turkey: distribution, diversity, and use. Crop Sci 56(6): 3112-3124

13. Zarkti H, Ouabbou H, Udupa SM, Gaboun F, Hilali A (2012) Agromorphological variability in durum wheat landraces of Morocco. Australian Journal of Crop Science 6(7): 1172-1178.

14. Feldman M (2001) Origin of cultivated wheat. In: Angus WJ (Eds.) The World Wheat Book: A History of Wheat Breeding, Bonjean AP and Anugus WJ (Eds.),Lavoisier Publishing, Paris, France, pp: 3-56.

15. Trethowan RM, Mujeeb Kazi A (2008) Novel germ plasm resources for improving environmental stress tolerance of hexaploid wheat. Crop Science 48(4): 1255-1265.

16. Ceccarelli S, Grando S, Van Leur JAG (1987) Genetic diversity in barley landraces from Syria and Jordan. Euphytica 36(2): 389-405. 
17. Backes G, Orabi J, Wolday A, Yahyaoui A, Jahoor A (2009) High genetic diversity revealed in barley (Hordeumvulgare) collected from smallscale farmer's fields in Eritrea. Genetic Resource and Crop Evolution 56(1): 85-97.

18. FAOSTAT (2008) Food and Agriculture Organization of the United Nations. Rome, Italy.
19. Brush SB (1994) In situ conservation of landraces in centers of crop diversity. Crop Sci 35(2): 346-354.

20. Lobell DB, Burke MB, Tebaldi C, Mastrandrea MD, Falcon WP, et al (2008) Prioritizing climate change adaptation needs for food security in 2030. Science 319(5863): 607-610.

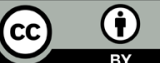

Creative Commons Attribution 4.0 International License

For possible submissions Click Here

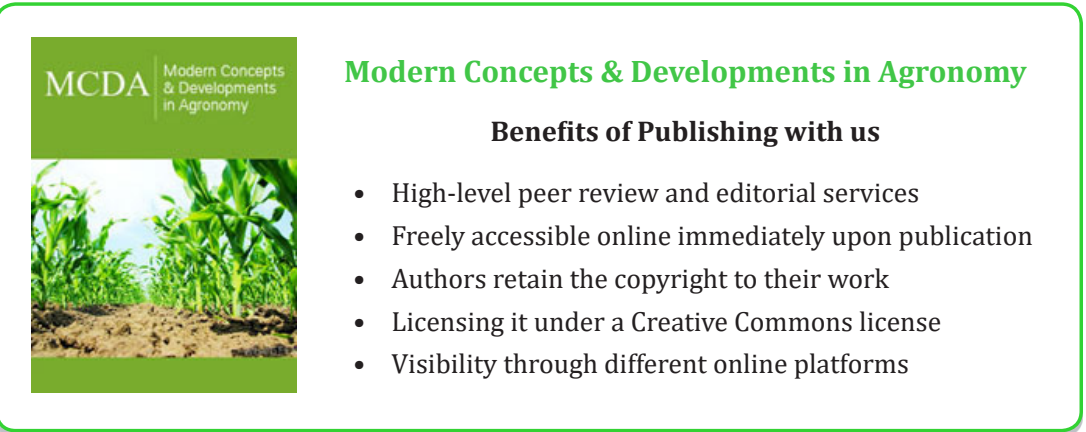

